\title{
RESULTS OF THE FIRST ARCTIC HEAT OPEN SCIENCE EXPERIMENT
}

\author{
Kevin R. Wood, Steven R. Jayne, Calvin W. Mordy, Nicholas Bond, \\ James E. Overland, Carol Ladd, Phyllis J. Stabeno, Alexander K. Ekholm, \\ Pelle E. Robbins, Mary-Beth Schreck, Rebecca Heim, and Janet Intrieri
}

The Arctic Heat Open Science Experiment is developing new real-time observing capabilities and strengthening collaboration among research laboratories and the National Weather Service in Alaska.

0 bserving the flow of solar energy through the Chukchi Sea during the entire cycle of melt and freeze is a longstanding challenge. Access to this domain is controlled by sea ice, which also constrains the observations that can be made. Oceanographic moorings must be kept below the deepest ice keels to avoid destruction, satellites only measure the

AfFILIATIONS: WOOD, MORDY, AND BOND-Joint Institute for the Study of the Atmosphere and Ocean, University of Washington, and NOAA/Pacific Marine Environmental Laboratory, Seattle, Washington; JAYNE, EKHOLM, AND RoBBINS-Physical Oceanography Department, Woods Hole Oceanographic Institution, Woods Hole, Massachusetts; OVerLAND, LAdD, ANd StABeno-NOAA/ Pacific Marine Environmental Laboratory, Seattle, Washington; SChreCK AND Heim—National Weather Service Sea Ice Program, Anchorage, Alaska; INTRIERI-NOAA/Earth System Research Laboratory, Boulder, Colorado CORRESPONDING AUTHOR: Kevin Wood, kevin.r.wood@noaa.gov

The abstract for this article can be found in this issue, following the table of contents.

DOI:10.1175/BAMS-D-16-0323.I

In final form 27 October 2017

(C)2018 American Meteorological Society

For information regarding reuse of this content and general copyright

information, consult the AMS Copyright Policy. near surface, and ships obtain very intermittent data, almost exclusively during summer. Lack of observations hampers sea ice and weather forecast services and contributes to large uncertainties in sea ice and climate projections and related climate and ecosystem impact assessments (e.g., Kattsov et al. 2010; Wang and Overland 2015). A new generation of air-deployable autonomous ocean observation systems offers considerable promise, especially those that combine endurance, subdaily resolution, and near-real-time data telemetry. Timely delivery of data is a distinguishing feature of these systems and will lead to improved weather and sea ice forecasts upon which maritime and coastal communities depend, reduce uncertainty in models and reanalyses, and speed ongoing research activities across disciplines.

The Arctic Heat Open Science Experiment aims to fill this observation gap using innovative technologies such as the marine robotic vehicles known as AirLaunched Autonomous Micro Observer (ALAMO) profiling floats (Jayne and Bouge 2017) and other weather and ocean sensing instruments carried on board a National Oceanic and Atmospheric Administration (NOAA) Twin Otter aircraft (NOAA-56). These observing systems provide an opportunity to monitor ocean heat content and related sea ice processes, movement and modification of different water 
masses, and to investigate the wider spatial structure within which observations occur. Leveraging data from multiple platforms, including satellite remote sensing and new marine autonomous systems, enables concurrent sampling of the atmosphere and ocean in the marginal ice zone when other observing technologies may be more limited.

Data are published online in near-real time for public and research community use and for collaborators at the National Weather Service (NWS) Alaska Sea Ice Program and other research laboratories. Data, technical details, and other information are available from the Arctic Heat website (www .pmel.noaa.gov/arctic-heat/); ALAMO float data are also available from the Woods Hole Oceanographic Institution ALAMO website (https://alamo.whoi .edu) and on the Global Telecommunications System (GTS; https://public.wmo.int/en/programmes/global -telecommunication-system). Open data amplify the

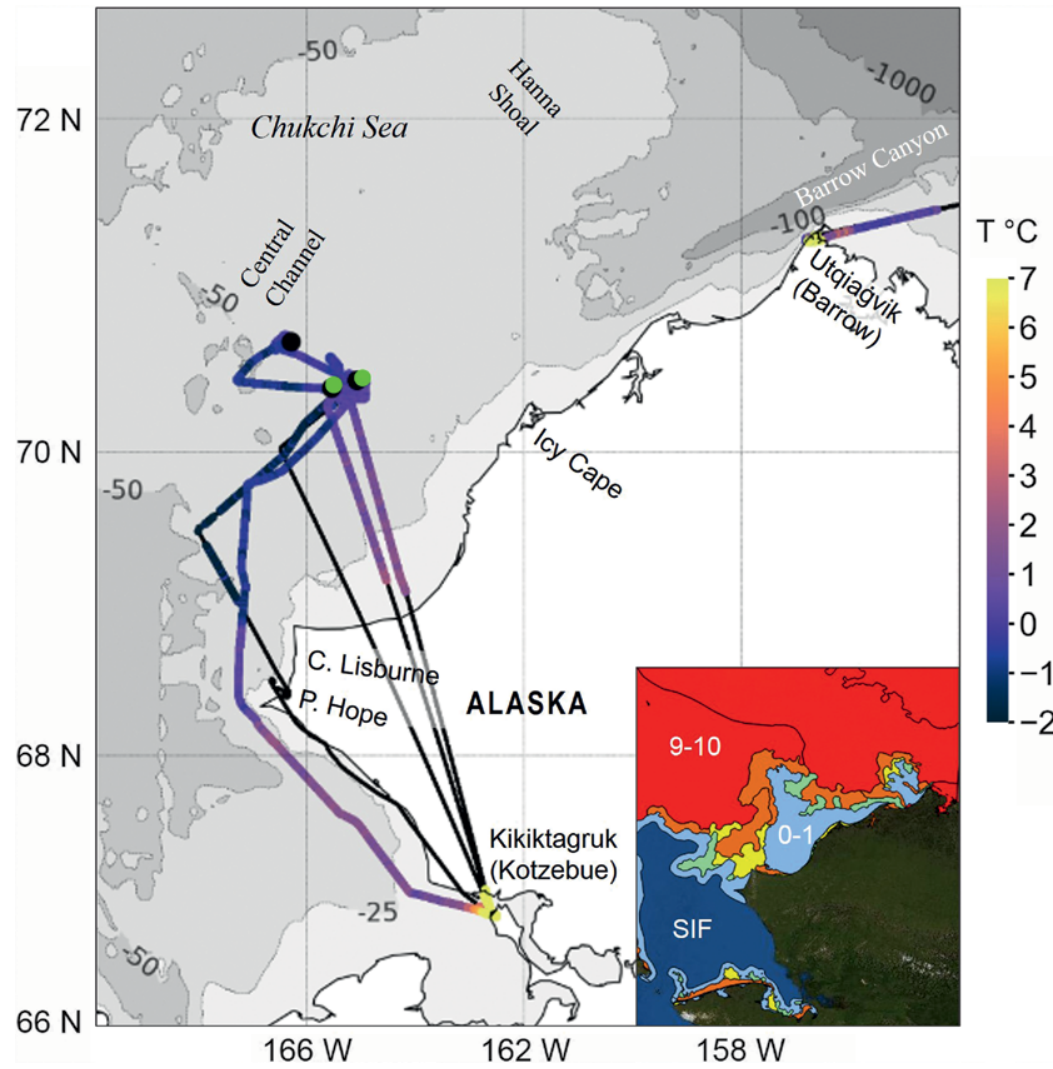

FIG. I. Arctic Heat flights in Jun 2016. Track color indicates SST from the aircraft radiometer while flying at $500 \mathrm{ft}(\mathrm{It} \approx 0.305 \mathrm{~m}$; thin black lines denote altitudes $>\mathbf{8 0 0} \mathrm{ft}$, where radiometer $\mathrm{SST}$ data are less reliable). Black circles show where AXBTs or AXCTDs were deployed; green circles mark ALAMO deployments. Bathymetry is shown by gray shading, with contours at 50,100 , and $1,000 \mathrm{~m}$. Inset shows the sea ice concentrations for the operating area from the NWS Alaska Sea Ice Program for 9 Jun (available from https://portal.aoos.org/arctic.php). Labels denote concentration in tenths or sea ice free (SIF). broader impact of science and forecast services on the safety and economic viability of marine and coastal community activities.

The 2016 field season was the first of a series expected to extend through the Year of Polar Prediction (2017-19). The main objectives in 2016 were to equip NOAA-56 with new meteorological instruments and air-deployment capability and to carry out combined scientific research and engineering development operations in the field. During nine flights in June and September, covering more than 6,000 miles, we collected flight-level weather data, sea surface temperature (SST), and downward shortwave radiometry, deployed 49 airborne expendable bathythermograph (AXBT) probes, 10 airborne expendable conductivity-temperature-depth (AXCTD) probes, 10 atmospheric dropsondes, and 6 ALAMO floats. The floats collected a combined 556 full water column profiles, including data received from two floats when they surfaced in a flaw lead near Point Barrow in April 2017.

This paper describes selected results from the 2016 field season, focusing on new perspectives afforded by ocean sensing capabilities of NOAA-56 and the ALAMO floats. Note that in our discussion of water masses observed by the ALAMO floats we use temperature and salinity ranges defined previously (e.g., Danielson et al. 2017; Gong and Pickart 2016). Two variants of the ALAMO were deployed: a depth-temperature (PT) model and a conductivity-temperaturedepth (CTD) model. We also discuss implications these instruments may have for forecasting and research in the future and the design of efficient observing technologies in the challenging Arctic domain.

\section{CHUKCHI SEA IN SPRING.}

The first three Arctic Heat flights over the Chukchi Sea occurred on 5-7 June 2016 from Kikiktagruk (Kotzebue), Alaska (Fig. 1). The goal for these flights was to field test the deployment system and performance of the ALAMO floats under early-melt-season 
conditions in the marginal ice zone and to monitor the warming of the water column as the season progressed. By this time, the winter sea ice had retreated to Point Hope, while most of the region to the north remained covered by $9 / 10$ to $10 / 10$ ice, except for a large polynya along the coast (Fig. 1, inset). Two ALAMO floats were deployed in this polynya. A fourth flight was carried out via Utqiagivik (formerly known as Barrow) and Deadhorse, Alaska, on 11 June to deploy two additional floats in the eastern Beaufort Sea (not shown).

Float 9058-PT was deployed on 5 June and first reported at $70.37^{\circ} \mathrm{N}, 165.34^{\circ} \mathrm{W}$. This float transmitted 71 profiles during a $380-\mathrm{km}$ drift into Barrow Canyon (Fig. 2). Mean drift velocity was $16 \mathrm{~cm} \mathrm{~s}^{-1}$, but interpretation in terms of current is complicated by the unknown effect of sustained-but probably gentle-interaction with the seafloor and the occasional periods when the float was held under the sea ice (indicated by the shaded areas in the temperature section in Fig. 2c). During the drift of 9058-PT, sea ice conditions along the track were difficult, with the polynya west of

Point Barrow closing on 10 June, leaving 7/10 to $10 / 10$ concentrations prevailing for the remainder of the drift. Nevertheless, 9058-PT transmitted profile data until 2 July when the float was trapped on the surface by the ice.

The temperature section (Fig. 2c) shows a warmer $\left(\sim 0.5^{\circ} \mathrm{C}\right)$ upper layer off Icy Cape that was 25-30 $\mathrm{m}$ thick (7-11 June). This upper layer was cooler near the ice (12-14 June) and thinned as the float approached Barrow Canyon. An intermediate layer of cold winter water $\left(-1.5^{\circ} \mathrm{C},>25\right.$-m depth on 7 June) shoaled to the northeast and surfaced over Barrow Canyon, likely caused by the sea ice inhibiting solar heating. A thin $(5 \mathrm{~m})$ bottom layer of warmer $\left(\sim 0.0^{\circ} \mathrm{C}\right)$ water appeared on 9 June, and as the float moved to the northeast, this warmer bottom layer increased in thickness. b

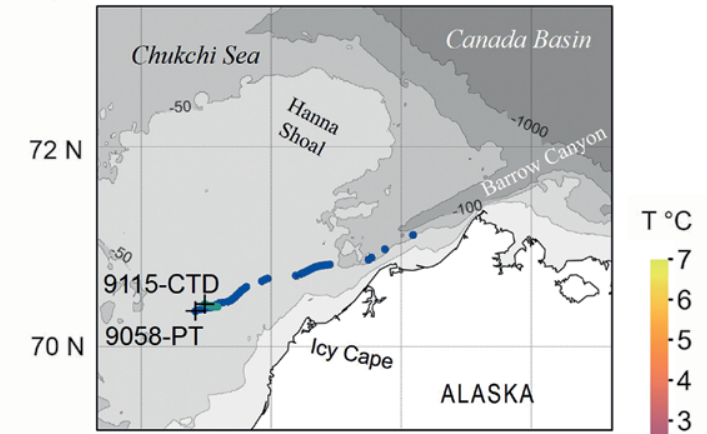

$167 \mathrm{~W} \quad 163 \mathrm{~W} \quad 159 \mathrm{~W} \quad 155 \mathrm{~W}$
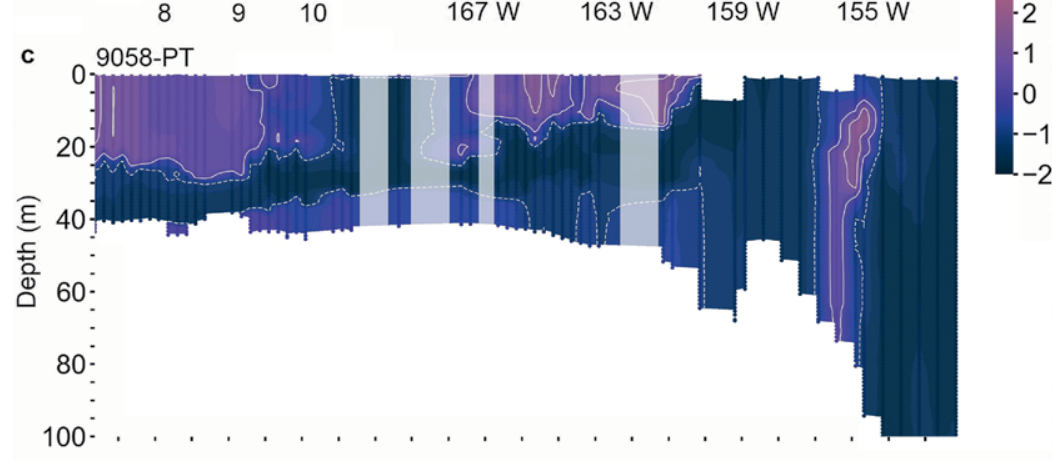

FIG. 2. (b) Deployment locations for floats 9058-PT and $9 / 1$ 5-CTD (+) and drift tracks (bathymetry as in Fig. I). (c) Temperature time series from ALAMO float 9058-PT and (a) temperature-salinity time series from upper layer, an intermediate layer of cold winter water, and a warmer, Water (AW). Contours are, respectively, temperature (light gray; $1{ }^{\circ} \mathrm{C}$ tervals, dashed below $0^{\circ} \mathrm{C}$ ) and salinity (green; 0.5-psu intervals). Shaded regions indicate where 9058-PT was temporarily stuck under ice and did not profile, while $\sim 6-\mathrm{m}$ notches at the surface are due to ice avoidance by the float. The $1.8^{\circ} \mathrm{C}$ water seen on 27-28 Jun may be dense Chukchi Summer Water (Gong and Pickart 2016).

Float 9115-CTD was deployed 6 June and first reported at $70.44^{\circ} \mathrm{N}, 165.05^{\circ} \mathrm{W}$. This float returned 13 profiles over 3 days before contact was lost because of battery failure. Enough data were obtained from 9115-CTD to describe salinities associated with the temperature structure (Fig. 2a) and by inference to $9058-\mathrm{PT}$. Salinities increased through the water column with a fresher upper layer $(<32 \mathrm{psu})$, an intermediate layer of winter water $(\sim 32.5 \mathrm{psu})$, and a thin bottom layer of saltier (>33.5 psu) water. This bottom layer was AW, likely upwelled via Barrow Canyon (Aagaard and Roach 1990; Bourke and Paquette 1976; Ladd et al. 2016; Pickart et al. 2011).

\section{AUTUMN TRANSITION AND FREEZE-UP.}

Five flights were carried out during 10-15 September, three from Utqiagivik and two from Kikiktagruk. The 
main goals of these flights were to obtain a synoptic map of ocean temperatures in the northeast Chukchi Sea at the sea ice minimum (10 September 2016) and to deploy two ALAMO PT floats to monitor the rate of cooling into freeze-up. The mapping component consisted of along-track SST surveys using an aircraft-mounted radiometer, complemented with depth profiles from AXBTs and AXCTDs (Fig. 3). Analyses from the NWS Alaska Sea Ice Program showed a band of moderately high sea ice concentration that extended northwesterly from the Alaskan coast (Fig. 3, inset) had persisted through the summer. This is reflected in unusually cold temperatures detected by both the aircraft radiometer and AX probes.

Synoptic characterization of the wider domain with a combination of AX probes and SST radiometry from the aircraft depends on knowing the relationship between the depth-temperature structure of the water column and the radiating surface layer only 10-20 $\mu \mathrm{m}$ thick (Donlon et al. 2007). Inspection of the AX data along with the first few profiles from the

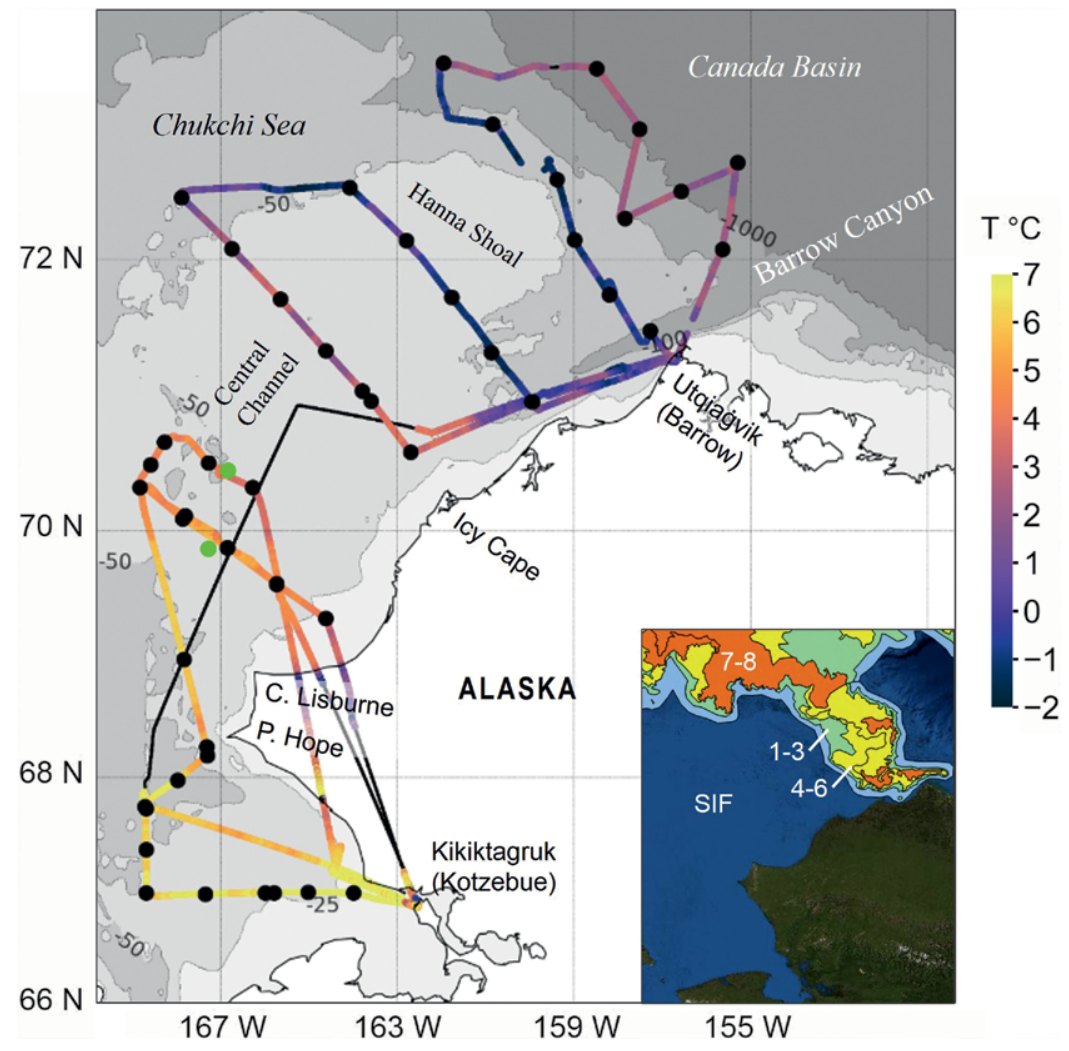

FIG. 3. Arctic Heat flights in Sep 2016. Track color indicates the SST from the aircraft radiometer while flying at $500 \mathrm{ft}$ (thin black lines denote altitudes $>800 \mathrm{ft}$ ). Black circles show the positions where AXBTs or AXCTDs were deployed, and green circles where ALAMO floats were deployed. Bathymetry is as in Fig. I. Inset shows the sea ice concentration analysis from the NWS Alaska Sea Ice Program for 15 Sep. Labels denote concentration in tenths or SIF.
ALAMO floats indicated that the water column was well mixed to $30-35 \mathrm{~m}$ nearly everywhere in midSeptember. The correlation of $0-35-m$ water column temperature with the aircraft radiometer was 0.96 and with 5-day-averaged SST from the Moderate Resolution Imaging Spectroradiometer (MODIS) on board the Aqua satellite was 0.84 (31 collocated samples).

On 15 September, ALAMO floats 9076-PT and 9085-PT were deployed at $69.9^{\circ} \mathrm{N}, 167.1^{\circ} \mathrm{W}$ and $70.5^{\circ} \mathrm{N}, 167.0^{\circ} \mathrm{W}$ (Fig. 4). Float $9085-\mathrm{PT}$ was deployed $60 \mathrm{~km}$ north of $9076-\mathrm{PT}$, with the idea that it would likely drift west of Hanna Shoal. This did occur initially, but it turned around on 7 October and drifted south of the shoal until converging with 9076-PT (Fig. 4b). A similar flow pattern has been observed using satellite-tracked drifters drogued at $30 \mathrm{~m}$ (Stabeno et al. 2018). Both floats lingered on the Chukchi shelf into winter. In April 2017, a flaw lead opened west of Point Barrow; both floats surfaced on 14 and 15 April and reported positions (and one profile), indicating a net velocity of $\sim 2 \mathrm{~cm} \mathrm{~s}^{-1}$, based on displacement from the lastknown positions prior to freezeup in December.

Both floats captured the seasonal transition from ice minimum to freeze-up (Fig. 4c). There was a distinct two-layer system from mid-September until late October. Mixing of heat into the bottom layer occurred from late-October through November. The average cooling rate of the upper $35 \mathrm{~m}$ was $0.04^{\circ} \mathrm{C}$ day $^{-1}$ from 15 September through 21 November $\left(-85 \mathrm{~W} \mathrm{~m}^{-2}\right.$; Fig. 4a). From 21 November through 28 November, sea ice advanced over the floats and cooling increased to $0.24^{\circ} \mathrm{C}_{\text {day }}{ }^{-1}$ $\left(-500 \mathrm{~W} \mathrm{~m}^{-2}\right)$. At this time the floats were placed in winter mode (profiling once every 5 days) in anticipation of overwintering under the ice.

DISCUSSION. The northeastern Chukchi Sea is shallow $(40-50 \mathrm{~m})$, with a prominent shoal to the north (Hanna Shoal, $30 \mathrm{~m}$ ), with Barrow Canyon as an important connection to the deep Arctic Ocean. Flow over 
the shelf is generally northward following bathymetry (Stabeno et al. 2018; Woodgate et al. 2005). Several water types enter onto the Chukchi shelf via the Bering Strait including Alaskan Coastal Water, Anadyr Water, and Bering Sea Water (Coachman et al. 1975; Danielson et al. 2017). In addition, intrusions of dense, salty AW appear on the shelf during upwelling events, often entering the shelf via Barrow Canyon (Bourke and Paquette 1976; Ladd et al. 2016; Pickart et al. 2009; Pickart et al. 2011). Hence, water properties over the shelf are a combination of advective and in situ processes (atmospheric fluxes, mixing, and ice formation $/$ melt).

Since 2010, the Ecosystems and Fisheries-Oceanography Coordinated Investigations (EcoFOCI) program at NOAA's Pacific Marine Environmental Laboratory (PMEL) has maintained a mooring array between Icy Cape and Barrow Canyon that collects near-bottom $(5-8 \mathrm{~m}$ above bottom) measurements of currents, temperature, and salinity (Fig. 5). During the winter and spring of 2016, upwelling events with southwestward flow were observed at C-4 near the head of Barrow Canyon. In June, as northeast flow returned, ALAMOs 9058-PT and 9115-CTD were deployed west of Icy Cape, and both floats detected AW within the bottom $5 \mathrm{~m}$ of the water column. This result was reminiscent of observations of AW far onto the shelf in August 1975 (Bourke and Paquette 1976). While AW has been observed at C-1 during previous years (Ladd et al. 2016), it was not detected during this event, even though 9058-PT passed within $14 \mathrm{~km}$ on 14 June. Instrumentation on C-1 was $\sim 5 \mathrm{~m}$ above the bottom and likely missed the bottom layer of $\mathrm{AW}$, recording instead the cold winter water layer above (Fig. 2). The three-layer temperature structure measured by the ALAMO floats has important implications for air-sea heat exchange in the Chukchi as well as exchange with the Arctic Basin, illustrating the utility of the float technology. If this thin layer of AW is common, it is likely that intrusions far onto the Chukchi shelf occur more frequently than observed by limited moored and shipboard measurements.

The mapping of the Chukchi Sea at sea ice minimum in September, and the deployment of two ALAMO floats, provided a synoptic characterization of conditions in the region at the beginning of freezeup, direct measurement of water column cooling, and quasi-Lagrangian flow estimates. NWS Alaska Sea Ice Program analysts used these data on an experimental ad hoc basis, along with georeferenced photographs of the ice collected on research flights, to augment sea ice analysis and forecast products through freeze-up. 
These data also provide an opportunity to investigate how much seasonal-scale predictive power may be conferred by enhanced real-time ocean observations.

Understanding how assimilating more observations will impact modeled analyses and short-term forecasts is of fundamental importance as new coupled models are developed. Preliminary results using a regional coupled model [Regional Arctic System Model (RASM) Earth System Research Laboratory (ESRL); A. Solomon 2017, personal communication]

\section{FREEZE-UP PROIECTION FOR THE CHUKCHI SEA}

$0^{n}$ 3 October 2017, PMEL issued an experimental seasonal projection for sea ice freeze-up for the Chukchi Sea offshore continental shelf. This projection was facilitated by in situ ocean observations from ALAMO 9119-CTD, along with analysis of $A X B T$ data and aircraft SST radiometry collected in mid-September, and long-term ice concentration data from satellite passive microwave radiometers (1979present). (For details, see www.pmel.noaa.gov/projected -onset-sea-ice-freeze-chukchi-sea-continental-shelf-2017.)

Freeze-up, defined here by sea ice concentration reaching $30 \%$ in the reference area northwest of Icy Cape (Fig. SBIa), was projected for the end of November to the first week of December 2017-more than I month later than the long-term mean date (198I-2010). Freeze-up occurred on 7 December 2017: 4 days later than 2016 and 43 days from the long-term mean. This was the first practical application of ALAMO toward improvement of long-range sea ice forecasting in the Chukchi Sea.

The water column sampled by ALAMO 9119-CTD in 2017 was warmer than during autumn of 2016 (Fig. SBIb) and consistent with the large SST anomaly observed in the region in August, as reported in the Arctic Report Card (www.arctic.noaa.gov/Report-Card). Most of the warmer water detected by ALAMO was in a salinity-stratified layer below 30-m depth and thus undetectable by satellite (Fig. SBIc). September temperatures in the upper $10 \mathrm{~m}$ were only $1.0^{\circ}-1.5^{\circ} \mathrm{C}$ higher than 2016 , while below $30 \mathrm{~m}$ they were up to $4.5^{\circ} \mathrm{C}$ higher. This was an important factor in setting the projected date of freeze-up in record territory.

Marked stratification at $\sim 30 \mathrm{~m}$ was present in September 2016 and 2017. It was surprising, however, that the water column was fully mixed by early November, rather than overturning during the ice formation and brine rejection process. This would imply that most of the heat initially sequestered below the mixed layer was lost to the atmosphere prior to freeze onset. The cooling rate in 2017 , as measured by 600 profiles, was also $\sim 50 \%$ faster than the previous year (Fig. SBIb).

Real-time profile data from 9119-CTD also contributed to understanding the performance of the RASM-ESRL regional coupled model throughout the progression of the unusual 2017 freeze-up season and will provide key information to review in the post forecast analysis period.

It is reasonable to expect that the anomalous freezeup conditions observed in 2017 may become typical in the central Chukchi Sea, especially in the absence of the secondyear and older sea ice that was present in the region in the past. In the future, cooling and freeze-up will occur solely through ocean heat loss directly to the atmosphere, under relatively greater influence of the annual solar cycle and a warmer Arctic climate.
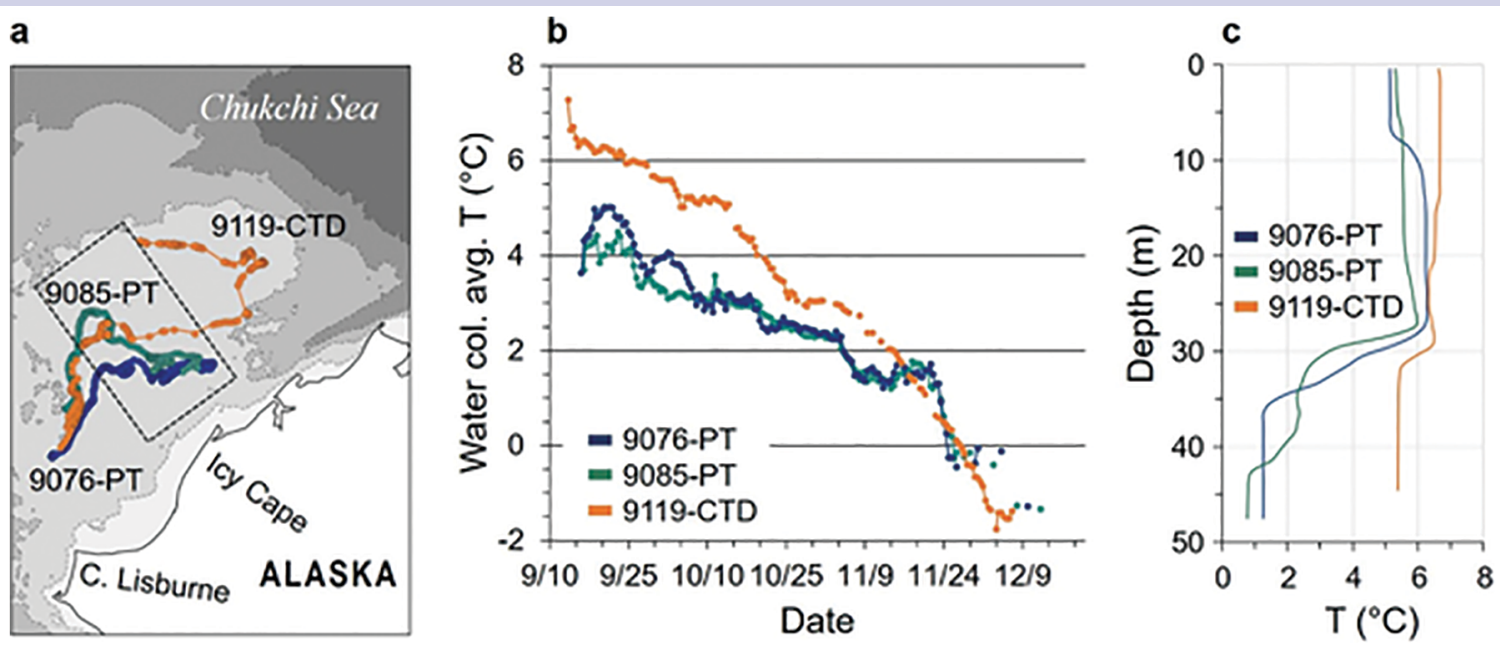

FIG. SBI. (a) Map showing the drift tracks of ALAMO floats in 2016 (blue: 9076-PT; green: 9085-PT) and 2017 (orange: 9119-CTD). The reference area for the PMEL freeze-up projection is marked by the box. (b) Seasonal change in water column temperature in the Chukchi Sea as measured by ALAMO floats in 2016 and 2017. (c) The 9119-CTD profile (orange) obtained on 19 Sep 2017 compared to profiles from the previous year. 
demonstrated that current ocean reanalyses do not include realistic representation of subsurface water masses relative to observations taken in 2015 and 2016 (including Arctic Heat data). Forecast experiments using a high-resolution fully coupled regional model show that these water masses impact sea ice evolution on synoptic time scales through upper-ocean mixing and heat flux at the ice-ocean interface. It is expected these effects will increase as sea ice continues to decline and surface heat flux processes increase. Future work will include evaluating the impact of assimilating enhanced ocean observations on modelbased analyses and short-term sea ice forecasts. This will allow us to explore fully coupled model data assimilation issues, better understand physical processes, and assess model performance in comparison to noncoupled (atmospheric) NWS model frameworks, especially relevant as NWS develops a new operational model.

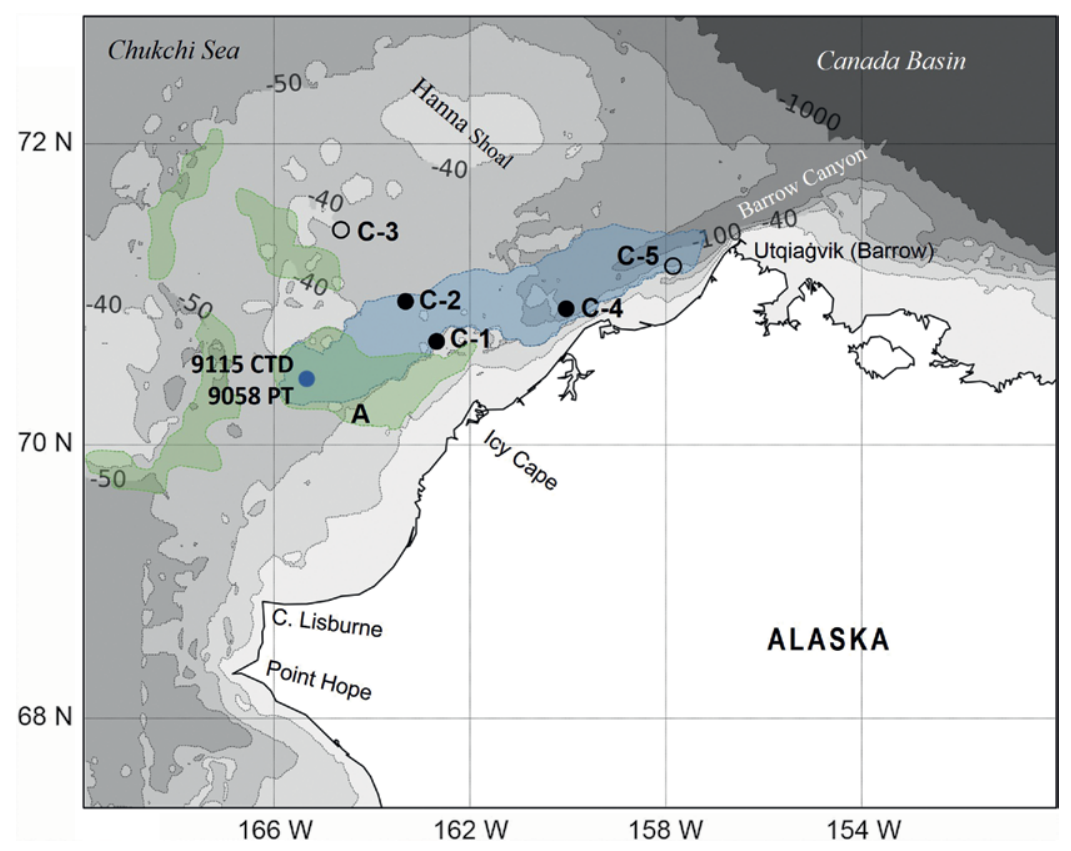

FIG. 5. The region where AW was observed on the Chukchi continental shelf in recent years by PMEL is depicted by blue shading (Ladd et al. 2016). ALAMO 9058-PT and 9II5-CTD deployment position is marked by the blue circle, and the PMEL mooring array (C-I through C-5) is indicated by black circles (filled circles show the location of moorings deployed in 2015-16; open circles indicate moorings deployed in previous years). Green shading indicates where AW was observed during the Marginal Ice Zone, Pacific (MIZPAC) program in 1975 (Bourke and Paquette 1976). Their temperature-salinity maximum $\left(1.04^{\circ} \mathrm{C}\right.$ and $33.62 \mathrm{psu}$ ) is marked by the letter A (see also their Fig. I).
CONCLUSIONS. The goals of the 2016 Arctic Heat Open Science Experiment were met on both science and engineering fronts. NOAA-56 proved a capable and efficient atmosphere-ocean research platform, largely because of sensor systems' design and integration accomplished by the engineers at the NOAA Aircraft Operations Center. A major advantage of the Twin Otter over heavier aircraft for the northern Alaska maritime region is its flexibility due to a light logistical footprint and remote field capability. As the 2016 season demonstrated, NOAA-56 can perform atmosphere-ocean research and deliver air-deployed autonomous systems at times and places rarely possible by other means.

The ALAMO float demonstrated anticipated endurance and capability by successfully profiling in one of the most challenging environments in the world. Not surprisingly at this stage of development, some improvements were identified. In particular, water-soluble materials used to secure the air delivery package dissolved too slowly in cold water, causing the parachute to stay attached for a day or more and leading to high power expenditures as the float worked against extra weight and drag. This and an unexpected battery fault contributed to the premature failure of three CTD floats. Ice detection is also being improved based on experience gained during 2016 deployments. ALAMOs 9076-PT and 9085-PT demonstrated physical under-ice endurance when they surfaced in April 2017 but were not able to offload logged data because of short surface time-out parameters.

The new capabilities of NOAA-56, combined with persistent, high-resolution, telemetered data from the ALAMO float, have brought new perspective on the seasonal characteristics of the Chukchi Sea, but they also highlight improvements needed in mooring design and limitations of ship observations. The detection of AW far up on the Chukchi shelf in 2016 (undetected by the mooring array), and the ability to fully monitor the onset of freeze over a period of months are two case-in-point examples. With autonomous systems we can obtain observations not feasible before, including near-real-time seafloor-to-surface profiles though much of the seasonal cycle. 
ACKNOWLEDGMENTS. This work was supported by NOAA Ocean and Atmospheric Research and the Joint Institute for the Study of the Atmosphere and Ocean (JISAO) under NOAA Cooperative Agreement NA15OAR4320063 and by the Innovative Technology for Arctic Exploration (ITAE) program at JISAO/PMEL. PMEL Contribution Number 4689 and JISAO Contribution Number 2017-094, EcoFOCI-0900. Jayne, Robbins, and Ekholm were supported by ONR (N00014-12-10110). The authors gratefully acknowledge the essential contribution of NOAA Corps officers and Aircraft Operations Center engineers and staff to the success of this project.

\section{REFERENCES}

Aagaard, K., and A. T. Roach, 1990: Arctic oceanshelf exchange: Measurements in Barrow Canyon. J. Geophys. Res., 95, 18 163-18 175, https://doi.org /10.1029/JC095iC10p18163.

Bourke, R. H., and R. G. Paquette, 1976: Atlantic water on the Chukchi shelf. Geophys. Res. Lett., 3, 629-632, https://doi.org/10.1029/GL003i010p00629.

Coachman, L. K., K. Aagaard, and R. B. Tripp, 1975: Bering Strait: The Regional Physical Oceanography. University of Washington Press, $172 \mathrm{pp}$.

Danielson, S. L., L. Eisner, C. Ladd, C. Mordy, L. Sousa, and T. J. Weingartner, 2017: A comparison between late summer 2012 and 2013 water masses, macronutrients, and phytoplankton standing crops in the northern Bering and Chukchi Seas. Deep-Sea Res. II, 135, 7-26, https://doi.org/10.1016/j .dsr2.2016.05.024.

Donlon, C., and Coauthors, 2007: The Global Ocean Data Assimilation Experiment High-Resolution Sea Surface Temperature Pilot Project. Bull. Amer. Meteor. Soc., 88, 1197-1213, https://doi.org/10.1175/BAMS -88-8-1197.

Gong, D., and R. S. Pickart, 2016: Early summer water mass transformation in the eastern Chukchi Sea.
Deep-Sea Res. II, 130, 43-55, https://doi.org/10.1016/j .dsr2.2016.04.015.

Jayne, S. R., and N. M. Bouge, 2017: Air-deployable profiling floats. Oceanography, 30, 29-31, https:// doi.org/10.5670/oceanog.2017.214.

Kattsov, V. M., V. E. Ryabinin, J. E. Overland, M. C. Serreze, M. Visbeck, J. E. Walsh, W. Meier, and X. Zhang, 2010: Arctic sea-ice change: A grand challenge of climate science. J. Glaciol., 56, 1115-1121, https://doi.org/10.3189/002214311796406176.

Ladd, C., C. W. Mordy, S. A. Salo, and P. J. Stabeno, 2016: Winter water properties and the Chukchi Polynya. J. Geophys. Res. Oceans, 121, 5516-5534, https://doi .org/10.1002/2016JC011918.

Pickart, R. S., G. W. K. Moore, D. J. Torres, P. S. Fratantoni, R. A. Goldsmith, and J. Yang, 2009: Upwelling on the continental slope of the Alaskan Beaufort Sea: Storms, ice, and oceanographic response. J. Geophys. Res., 114, C00A13, https://doi .org/10.1029/2008JC005009.

—, M. A. Spall, G. W. K. Moore, T. J. Weingartner, R. A. Woodgate, K. Aagaard, and K. Shimada, 2011: Upwelling in the Alaskan Beaufort Sea: Atmospheric forcing and local versus non-local response. Prog. Oceanogr., 88, 78-100, https://doi.org/10.1016/j .pocean.2010.11.005.

Stabeno, P., N. Kachel, C. Ladd, and R. Woodgate, 2018: Flow patterns in the eastern Chukchi Sea: 2010-2015. J. Geophys. Res., https://doi.org /10.1002/2017JC013135, in press.

Wang, M., and J. E. Overland, 2015: Projected future duration of the sea-ice-free season in the Alaskan Arctic. Prog. Oceanogr., 136, 50-59, https://doi .org/10.1016/j.pocean.2015.01.001.

Woodgate, R. A., K. Aagaard, and T. J. Weingartner, 2005: A year in the physical oceanography of the Chukchi Sea: Moored measurements from autumn 1990-1991. Deep-Sea Res. II, 52, 3116-3149, https:// doi.org/10.1016/j.dsr2.2005.10.016. 